\title{
Chronic myeloid leukemia: past, present, future
}

\author{
Leucemia mieloide crônica: passado, presente, futuro \\ Patricia Weinschenker Bollmann ${ }^{1}$, Auro del Giglio ${ }^{2}$
}

\begin{abstract}
The discovery of the Philadelphia chromosome in 1960, and of the BCR-ABL oncogene in 1984, enabled the development in subsequent years of a targeted therapy that revolutionized the treatment of chronic myeloid leukemia, thus changing its natural history. The use of imatinib resulted in a significant improvement of the prognosis and outcome of patients with chronic myeloid leukemia. However, the occurrence of mechanisms of resistance or intolerance precludes the eradication of the disease in some of the patients. Second-generation tyrosinekinase inhibitors are efficient in most of these patients, except for those with T315I mutation. We present an overall review of chronic myeloid leukemia, with emphasis on the progress in its treatment.
\end{abstract}

Keywords: Leukemia, myelogenous, chronic, BCR-ABL positive / therapy; Protein kinase inhibitors/therapeutic use; Drug resistance

\section{RESUMO}

As descobertas do cromossomo Filadélfia, em 1960, e do oncogene BCR-ABL, em 1984, permitiram o desenvolvimento, nos anos subsequentes, de uma terapia-alvo que revolucionou o tratamento da leucemia mieloide crônica, mudando sua história natural. 0 uso do imatinibe resultou numa melhora expressiva do prognóstico e da evolução dos pacientes com leucemia mieloide crônica. Entretanto, surgiram mecanismos de resistência ou intolerância, que impedem a erradicação da doença numa parcela dos pacientes. Os inibidores de tirosina quinase de segunda geração mostram eficácia na maioria desses pacientes, exceto naqueles com mutação T315I. Aqui, foi realizada uma revisão global da leucemia mieloide crônica, destacando-se a evolução de seu tratamento.

Descritores: Leucemia mielogênica crônica BCR-ABL positiva/ terapia; Inibidores de proteínas quinases/uso terapêutico; Resistência a medicamentos

\section{INTRODUCTION}

Chronic myeloid leukemia (CML) is a myeloproliferative disorder characterized by the presence of an acquired mutation which affects the hematopoietic stem cell.
CML accounts for $20 \%$ of leukemias in adults and its frequency is similar worldwide. Its anual incidence is of 1.6 cases/100,000 inhabitants/year, with a slight predominance in males (1.4/1.3), and the median age at presentation is 55 years. Less than $10 \%$ of cases occur in patients under 20 years of age ${ }^{(1)}$.

A higher incidence of CML is seen among survivors of the atomic bomb attack during World War II, as well as among patients undergoing radiation therapy for the treatment of malignancies. Despite the likely causal relation between CML and ionizing radiation, most of the cases seem to be sporadic, with no predisposing factor.

\section{PATHOPHYSIOLOGY}

In 1960, a minute chromosome was identified in patients with $\mathrm{CML}^{(2)}$. For the first time in the history of Medicine, the association between a chromosome abnormality and a malignant disease was described. Later, this chromosome abnormality was proven to result from a reciprocal and balanced translocation between the long arms of chromosomes 9 and $22 \mathrm{t}(9 ; 22)(\mathrm{q} 34 ; \mathrm{q} 11)$, and was called Philadelphia $(\mathrm{Ph})$ chromosome. Present in $95 \%$ of patients with $\mathrm{CML}$, the $\mathrm{Ph}$ chromosome results from the balanced translocation between the ABL (Abelson Murine Leukemia) gene located on chromosome 9, and the BCR (breakpoint cluster region) gene on chromosome $22^{(2,3)}$. The resulting hybrid gene - BCRABL, codifies an abnormal fusion protein that possesses tyrosine kinase (TK) activity continuously activated in the $\mathrm{ABL}$ region, and is responsible for the development of leukemia.

From the identification of the molecular pathogenesis of CML, efforts have been made to identify the signaling pathways that influence the BCR-ABL TK activity, linking these pathways to the characteristic changes of CML. These changes include: increased cell proliferation (RAS pathway

\footnotetext{
${ }^{1}$ Hematology and Bone Marrow Transplantation, Hospital Israelita Albert Einstein - HIAE - São Paulo (SP), Brazil.

${ }^{2}$ Faculdade de Medicina do ABC - FMABC, Santo André (SP), Brazil; Hospital Israelita Albert Einstein - HIAE - São Paulo (SP), Brazil.

Corresponding author: Patricia Weinschenker Bollmann - Centro de Oncologia e Hematologia - HIAE - Avenida Albert Einstein, $627 / 701$ - Morumbi - CEP 05651-901 - São Paulo (SP), Brasil - Tel.: (11) 2151-0240 - e-mail: patriciawb@terra.com.br

Received: Jan 24, 2011 - Accepted: May 05, 2011
} 
activation); decreased apoptosis (STAT5 pathway, hyperactivation of the anti-apoptotic molecule BCLxI, inactivation of the pro-apoptotic molecule BAD via AKT); cell adhesion deregulation, with premature release of immature myeloid cells in the circulation (CRKL effect); changes in angiogenesis; and increased genomic instability accounting for disease progression ${ }^{(4,5)}$.

The finding of this molecular abnormality not only facilitated an accurate diagnosis of CML, but also enabled the development of a therapy targeted at this molecular defect and, later, of techniques for monitoring minimal residual disease ${ }^{(6)}$.

\section{CLINICAL COURSE}

CML has an initial chronic phase (CP) of variable duration, and then progresses to the blast phase (BP), which is preceded or not by an accelerated phase (AP). Approximately $90 \%$ of patients are diagnosed in the CP, and $20 \%$ to $45 \%$ of them are asymptomatic. They present with leukocytosis with left shift, welldifferentiated granulocytic cells and enlarged spleen. When symptomatic, they present with symptoms of hypercatabolism (fatigue, weight loss, night sweats and fever) and abdominal discomfort due to spleen enlargement. Thrombotic complications or hemorrhage occur in less than $5 \%$ of the cases in CP.

Patients may suddenly progress from $\mathrm{CP}$ to $\mathrm{BP}$ or go through a transition period, the accelerated phase $(\mathrm{AP})^{(7)}$.

Several definitions of AP have been described in the past 20 years; those more frequently used are MD Anderson Cancer Center's (MDACC), International Blood and Marrow Transplantation's (IBMTR) and the World Health Organization's (WHO) ${ }^{(8)}$. In all these classifications, there are objective criteria, such as the number of blasts, basophils, and evidence of clonal evolution, in addition to more subjective criteria such as persistent leukocytosis and spleen enlargement unresponsive to treatment (Chart 1).

Chart 1. Comparison of three classifications of CML in accelerated phase

\begin{tabular}{|c|c|c|c|}
\hline Cell types & MDACC & IBMTR & WHO \\
\hline Blasts (\%) & $\geq 15$ & $\geq 10$ & $10-19$ \\
\hline Blasts + promyelocytes (\%) & $\geq 30$ & $\geq 20$ & NA \\
\hline Basophils (\%) & $\geq 20$ & $\geq 20$ & $\geq 20$ \\
\hline Platelets $\left(/ \mathrm{mm}^{3}\right)$ & $<100,000$ & $\begin{array}{l}\text { persistent } \uparrow \text { or } \\
\downarrow \text {, independent } \\
\text { from treatment }\end{array}$ & $\begin{array}{l}<100,000 \text { or } \\
>1,000,000\end{array}$ \\
\hline Leukocytes $\left(/ \mathrm{mm}^{3}\right)$ & NA & Difficult control & NA \\
\hline Anemia & NA & $\begin{array}{l}\text { Not responsive } \\
\text { to treatment }\end{array}$ & NA \\
\hline Splenomegaly & NA & Increasing & NA \\
\hline Cytogenetics & Clonal evolution & Clonal evolution & Clonal evolution \\
\hline
\end{tabular}

MDACC: MD Anderson Cancer Center; IBMTR: International Bone Marrow Transplant Registry; NA: not applicable.
After a period of 1 to 2 years, the AP turns into myeloid BP (70\%), lymphoid BP (20\% to $30 \%)$ or undifferentiated BP, characterized by infections, bleeding, multiple organ failure, with a mean survival of 3 to 6 months if untreated ${ }^{(7)}$.

Transition from CP to more advanced stages of the disease is not well understood, but it is believed to result from genomic instability. BCR-ABL-induced cell proliferation would lead to the acquisition of additional chromosome abnormalities, known as clonal evolution $^{(9)}$.

\section{PROGNOSTIC FACTORS}

For an early identification of patients in the $\mathrm{CP}$ of the disease who could have an unfavorable outcome with conventional therapy, Sokal ${ }^{(10)}$, in 1984, developed a system to sub-classify patients with CP-CML into three groups according to survival and clinical and laboratory characteristics (platelet count, spleen size, age, and percentage of circulating blasts). A similar prognostic score was developed by Hasford et $\mathrm{al}^{(11)}$ using the following parameters: age, spleen size, peripheral platelet count, eosinophils, basophils and blasts. Both scores remain highly reproducible today and accepted as prognostic models for $\mathrm{CP}$ patients (Chart 2).

Chart 2. Risk score in chronic myeloid leukemia

\begin{tabular}{|lcccc|}
\hline Risk & Sokal & $\begin{array}{c}\text { Median } \\
\text { survival }(\mathbf{m})\end{array}$ & Hasford & $\begin{array}{c}\text { Median } \\
\text { survival }(\mathbf{m})\end{array}$ \\
\hline High & $<0.8$ & 60 & $\leq 780$ & 98 \\
Intermediate & $0.8-1.2$ & 30 & $781-1480$ & 65 \\
Low & $>1.2$ & 24 & $>1480$ & 42 \\
\hline
\end{tabular}

Link for online calculation: www.roc.se/sokal.asp; www.phamacoepi.de

$\mathrm{m}=$ months

\section{TREATMENT}

The treatment of CML has gone through a real revolution throughout the years. Palliative splenic radiotherapy, started in the early 20th century, remained the standard therapy for more than 50 years. In 1960, busulfan emerged ${ }^{(12)}$, and later, hydroxyurea, which proved superior to busulfan, probably for being better tolerated, and a slight gain in survival was observed $^{(13)}$. However, none of these agents was able to suppress the $\mathrm{Ph}$ chromosome, and they were therefore unable to change the natural history of the disease.

In 1980, the efficacy of interferon-alpha (IFN- $\alpha$ ) in establishing hematologic and cytogenetic responses, whether partial or complete, was confirmed, and survival was thus prolonged ${ }^{(14)}$. Gradually, IFN- $\alpha$ replaced hydroxyurea and busulfan in the management of patients with newly-diagnosed $\mathrm{CP}^{(15)}$.

Also in 1980, the first experiences with allogeneic hematopoietic stem cell transplantation (AHSCT) 
in $\mathrm{CP}-\mathrm{CML}$ were carried out, representing the first curative modality, with a transplant-related mortality of $10 \%$ to $20 \%$ at one year and five-year survival of approximately $60 \%{ }^{(16)}$, and a high percentage of patients with no evidence of disease. Patients occasionally with relapse were successfully rescued by means of donor lymphocyte infusion, with or without previous chemotherapy ${ }^{(17)}$. It became evident that the benefit obtained with AHSCT in CML is a result of the graft-versus-leukemia effect, mediated by donor lymphocytes, although the specific target of this effect remains not fully identified ${ }^{(18)}$. As from 1990, AHSCT became the treatment of choice for $\mathrm{CP}$ patients less than 50 years old, and IFN, whether in combination with cytarabine or not, was reserved for patients not eligible for AHSCT ${ }^{(19)}$. The discovery of the BCRABL oncoprotein in 1986 enabled the development, in subsequent years, of a new drug able to inhibit the BCRABL oncoprotein activity ${ }^{(20)}$. Initially denominated STI571, and known today as imatinib, it revolutionized the treatment of CML.

CML then became the first disease model of the so-called targeted therapy. Although imatinib does not act directly in the base of the pathogenesis of CML preventing BCR-ABL codification, it competes for the ATP linking site of tyrosine kinase, thus restoring its cell death mechanism. Druker et al's in vivo and in vitro studies showed that this drug reduces by between $92 \%$ and $98 \%$ the number of BCR-ABL colonies, but without inhibiting normal colony formation ${ }^{(21)}$.

Imatinib was first used in 1998 to treat IFN-resistant patients $^{(22)}$. The successful results of this small study led to the development of the IRS study (International Randomized Study of Interferon and STI 571), which demonstrated the superiority of imatinib $400 \mathrm{mg} / \mathrm{dl}$ in relation to the IFN and cytarabine combination, regarding the rates of cytogenetic response $(\mathrm{CgR})$, event-free survival (EFS), progression-free survival (PFS) and overall survival (OS) ${ }^{(23)}$. After the year of 2000, imatinib, at the dose of $400 \mathrm{mg} /$ day, became the first-choice treatment for patients with CP CML. Initial imatinib doses of $800 \mathrm{mg}$ were compared to $400 \mathrm{mg}$ in the TOPS study ${ }^{(24)}$. In the French study SPIRIT, the 400 $\mathrm{mg} /$ day dose was compared to $600 \mathrm{mg} / \mathrm{day}^{(25)}$. Despite the observation that patients receiving higher imatinib doses achieved complete cytogenetic response ( $\mathrm{CCgR})$ sooner, no advantage regarding survival has been demonstrated to date.

The combination of imatinib $400 \mathrm{mg} /$ day with pegylated IFN alpha-2b was analyzed in two studies of $\mathrm{CP}$ patients and, despite the higher rates of $\mathrm{CCgR}$ and major molecular response (MMR), most of the patients discontinued IFN after one year of treatment ${ }^{(25,26)}$.
After the introduction of imatinib, new criteria for response and disease monitoring emerged with the objective of optimizing and standardizing the management of CML. These criteria were created by the Leukemia Net group ${ }^{(27)}$ by means of a critical review of relevant articles of the literature and consensus meetings.

\section{DEFINITION OF RESPONSE}

Complete hematologic response (CHR) is defined by: platelets $\leq 450 \times 10^{9} / \mathrm{L}$; leukocytes $\leq 10 \times 10^{9} / \mathrm{L}$, with normal differential blood count; basophils $<5 \%$; and absence of spleen enlargement.

The CgR may be complete (absence of $\mathrm{Ph}+$ cells), partial (Ph present in 1\% to $35 \%$ of the cells), minor ( $\mathrm{Ph}$ present in $36 \%$ to $65 \%$ of the cells), minimal ( $\mathrm{Ph}$ present in $66 \%$ to $95 \%$ of the cells), or absent ( $\mathrm{Ph}$ present in more than $95 \%$ of the cells).

MMR is defined by a three-log reduction in BCR$\mathrm{ABL}$ transcripts and corresponds to a BCR-ABL/ $\mathrm{ABL} \leq 0.1 \%$, as standardized by the international scale ${ }^{(28)}$; complete molecular response (CMR) is defined by the absence of BCR-ABL transcripts by RT-PCR and/or nested PCR in two consecutive samples (Chart 3).

Chart 3. Definition of hematological, cytogenetic and molecular response, and monitoring

Complete hematological response

- $\quad$ Platelets $\leq 450 \times 10^{9} / \mathrm{L}$

- Leukocytes $\leq 10 \times 10^{9} / \mathrm{L}$, with normal differential count

- $\quad$ Basophil $<5 \%$

- With no splenomegaly

Monitoring: each 2 weeks up to complete response. After, at every 3 months

Cytogenetic response

Complete: absence of $\mathrm{Ph}$

Partial: $\mathrm{Ph}(+)$ in 1 - $35 \%$ of cells

Minor: $\mathrm{Ph}(+)$ in $36-65 \%$ of cells

Minimum: $\mathrm{Ph}(+)$ in $66-95 \%$ of cells

No response: $>95 \%$ of cells with $\mathrm{Ph}(+)$

Monitoring: upon diagnosis, 3 months, and every 6 months, up to CCyR; later, once a year, whenever the treatment fails or in case of unexplainable cytopenias

\section{Molecular response}

Complete: mRNA BCR-ABL transcripts undetectable by RT-PCR and/or nested PCR in 2 consecutive samples

Major: $\mathrm{BCR}-\mathrm{ABL} / \mathrm{ABL}$ rate $<0.1 \%$, standardized by international scale, corresponding to reduction by $\geq 3$ logs of BCR-ABL transcripts

Monitoring: every 3 months up to achieving and confirming MMR; later, at every 6 months

The mutational analysis should be performed in cases of failure, suboptimal response or increase in number of transcripts, before change of ITK

Ph: Philadelphia chromosome; RT-PCR: real-time polymerase chain reaction; ITK: tyrosine kinase inhibitor

Based on the degree of hematologic, cytogenetic and molecular response, and on the time needed to achieve response, the response to imatinib may be defined as optimal, sub-optimal or failed (Chart 4). An 
Chart 4. Definition of response to imatinib in patients with chronic myeloid leukemia in early chronic phase

\begin{tabular}{|lcccc|}
\hline Response & $\mathbf{3}$ months & $\mathbf{6}$ months & $\mathbf{1 2}$ months & $\mathbf{1 8}$ months \\
\hline Optimal & $\begin{array}{c}\mathrm{CHR} \\
<\text { minor CgR }\end{array}$ & PCgR & PCgR & MMR \\
Suboptimal & With no CgR & $<\mathrm{PCgR}$ & $\mathrm{PCgR}$ & $<\mathrm{MMR}$ \\
Failure & With no CHR & With no CgR & $<\mathrm{PCgR}$ & $<\mathrm{CCgR}$ \\
\hline
\end{tabular}

CHR: complete hematological response; PCgR: partial cytogenetic response; CCgR: complete cytogenetic response; MMR: major molecular response; failure: at any time of no HR, no CCgR or presence of mutation.

optimal response means that a change in therapy is not indicated, with a probably increased survival, which is estimated at close to $100 \%$ after 6 to 7 years; a suboptimal response means that the patient still benefits from treatment continuation, but could be eligible to an alternative treatment; A failed response means that a favorable outcome is unlikely and the patient should receive a different treatment, provided that it is available and applicable. These definitions of response can also be modulated by prognostic factors that may adversely affect the response to treatment and which thus require a more careful monitoring such as Sokal high-risk patients presenting with clonal evolution to the diagnosis, patients not achieving MMR at 12 months, or also those with increased BCR-ABL transcripts.

With the introduction of second-generation tyrosine-kinase inhibitors (TKI), the definition, albeit preliminary, of new response criteria $^{(27)}$ became necessary (Chart 5).

Chart 5. Definition of response to second-generation tyrosine kinase inhibitors (as second-line therapy) with chronic myeloid leukemia in chronic phase, who are intolerant or resistant to imatinib

\begin{tabular}{|lccc|}
\hline Response & $\mathbf{3}$ months & $\mathbf{6}$ months & $\mathbf{1 2}$ months \\
\hline Suboptimal & Smaller CgR & PCgR & $<\mathrm{MMR}$ \\
Failure & With no CgR & Minimum CgR & PCgR \\
& New mutations & New mutations & New mutations \\
\hline
\end{tabular}

CgR: cytogenetic response; PCgR: partial cytogenetic response;

MMR: major molecular response.

\section{MONITORING THE RESPONSE TO TREATMENT}

Monitoring the response to imatinib requires complete blood count, cytogenetic study and quantification of BCR-ABL transcripts ${ }^{(27)}$ (Chart 3). Complete blood count should be determined every 2 weeks, until a complete response is achieved, and then every 3 months. Cytogenetic study should be performed at diagnosis, at 3 months, and every 6 months until $\mathrm{CCgR}$, and then yearly and whenever unexplainable treatment failure or cytopenia occurs. BCR-ABL transcripts should be quantified using the RT-PCR technique every 3 months until MMR is achieved and confirmed.

Mutational analysis should be performed in cases of failure, sub-optimal response or increased number of transcripts, before TKI is changed.
The 8-year follow-up of the IRIS study showed a $\mathrm{CCgR}$ rate in $83 \%$ of patients, with an 8 -year projected EFS and OS of $81 \%$ and $85 \%$, respectively ${ }^{(29)}$. However, despite these results, approximately $1 / 3$ of patients did not have a favorable outcome: $17 \%$ of patients never achieved $\mathrm{CCgR} ; 15 \%$ achieved $\mathrm{CCgR}$, but lost it throughout time; and 5\% presented with intolerance to imatinib, and new strategies were necessary ${ }^{(29,30)}$.

Resistance to imatinib may be primary or secondary. In primary resistance, the patient shows no response since the beginning of treatment, whereas in secondary resistance the patient initially shows response, but then relapses. The resistance mechanisms may be BCRABL dependent or not. The BCR-ABL-dependent mechanisms include ABL sequence amplification and point mutations in the ABL molecule, which change its conformation and impede imatinib bonds ${ }^{(31,32)}$. The ABL-independent resistance mechanisms, which are therefore responsible for primary imatinib resistance, include: drug efflux by means of P-glycoprotein expression, although it is not precisely known whether this mechanism is clinically relevant; low OCT-1 cell transporter activity (33); imatinib binding to alpha-1 acid glycoprotein (AGP) ${ }^{(34)}$, which reduces its activity; activation of other signaling pathways such as the Ras/ Raf/Mek kinase, $\operatorname{Src}^{(35)}$.

Among the resistance mechanisms, point mutations in the BCR-ABL oncogene are the most common cause, occurring in $35 \%$ to $70 \%$ of patients with secondary resistance ${ }^{(36)}$. With the purpose of rescuing imanatibresistant or intolerant patients, second-generation TKI emerged.

\section{Second-generation TKI}

\section{Dasatinib}

Dasatinib, a piperazinyl derivative, has a potent inhibitory action against the Src and ABL kinases, including the active BCR-ABL conformation, and most of the mutant forms, except for the T315I mutation ${ }^{(37,38)}$. In 2006, dasatinib $70 \mathrm{mg}$ twice daily was approved for the treatment of CP, AP and BP CML patients, as well as of imatinib-resistant or intolerant patients.

In the START-R study, patient who had failed with imatinib at 400 and $600 \mathrm{mg}$ doses were randomized 2:1 for dasatinib $70 \mathrm{mg}$ twice daily or imatinib $800 \mathrm{mg}$. After 2 years, the major $\mathrm{CgR}$ was $53 \%$ in the dasatinib arm and $33 \%$ in the high-dose imatinib arm. Dasatinib also proved superior as regards $\mathrm{CCgR}(44 \%$ versus $18 \%)$ and MMR (29\% versus $12 \%)^{(39)}$.

A prospective study randomized four different dasatinib doses, and found that the $100 \mathrm{mg}$ dose once daily was effective and better tolerated in relation to the other doses for CP patients ${ }^{(40)}$. 
Imatinib-intolerant $\mathrm{CP}$ patients showed major $\mathrm{CgR}$ and CCgR rates of $76 \%$ and $75 \%$, respectively in one study, and $71 \%$ and $63 \%$, respectively, in another study ${ }^{(41,42)}$. Imatinib-resistant $\mathrm{CP}$ patients had major $\mathrm{CgR}$ and $\mathrm{CCgR}$ rates of $51 \%$ and $40 \%$, respectively, in one study, and $50 \%$ and $36 \%$, respectively, in another ${ }^{(40-42)}$.

The median time to achieve response was 5.5 months ${ }^{(43)}$, with response sustained for 2 years in $\mathrm{CP}$ patients, with PFS of $80 \%$ and OS of $90 \%$.

A multinational study randomized 519 newlydiagnosed CP CML patients to receive dasatinib 100 $\mathrm{mg}$ once daily or imatinib $400 \mathrm{mg}$ once daily. After a 12month follow-up, dasatinib proved superior in relation to the $\mathrm{CCgR}$ rate $(77 \%$ versus $66 \%, \mathrm{p}=0.007)$ and in relation to the MMR rate ( $46 \%$ versus $28 \%, \mathrm{p}<0.0001$ ). Responses were achieved earlier with dasatinib (46\% versus $28 \%, \mathrm{p}<0.0001)$. The rate of progression to AP was lower in the dasatinib arm $(1.9 \%$ versus $3.5 \%)$. The toxicity profile was similar ${ }^{(44)}$.

Among the adverse events of dasatinib, we should point out grade 3 and 4 myelotoxicity, neutropenia in $21 \%$, thrombocytopenia in $19 \%$, and anemia in $10 \%$. Non-hematologic adverse effects, all grades 1 or 2 , include: pleural effusion (10\%), diarrhea (17\%), rash $(11 \%)$, and headache $(12 \%)^{(45)}$. Recently, dasatinib was approved at the dose of $100 \mathrm{mg}$ once daily for imatinibresistant or intolerant CP patients ${ }^{(45)}$, and $140 \mathrm{mg}$ once daily for AP or BP patients ${ }^{(45)}$. Studies show similar response rates, with a more favorable toxicity profile, especially in relation to pleural effusion ${ }^{(46,47)}$, at the once daily dosage.

\section{Nilotinib}

Nilotinib, an amilopyrimidine derivative, inhibits TK activity of BCR-ABL, PDGF, c-kit, and most of the mutant forms of ABL, except for the T315I mutation, and is more potent and selective than imatinib ${ }^{(48-53)}$. It only binds to BCR-ABL in its inactive conformation.

In 2007, nilotinib was approved for the treatment of imatinib-resistant or intolerant CP CML patients and AP patients, at the dose of $400 \mathrm{mg}$ twice daily. It is well tolerated, and the most common grade- 3 and 4 laboratory abnormalities are: elevated lipase (17\%), hypophosphatemia (16\%), hyperglycemia (12\%) and elevated total bilirubin (8\%). The grade- 3 and 4 hematological changes were neutropenia (31\%), thrombocytopenia (31\%), and anemia (10\%). Grade-3 and 4 pleural or pericardial effusion occurred in less than $1 \%{ }^{(54)}$.

The CML-CP study showed the effect of nilotinib in 321 imatinib-resistant $(30 \%)$ or intolerant $(70 \%)$ $\mathrm{CP}$ patients in a follow-up of at least 19 months. Responses obtained showed a major CgR rate in 59\% achieved in a median time of 2.8 months, and $\mathrm{CCgR}$ in $44 \%$ of patients with a median time of 3.3 months. The responses were sustained after 24 months $(\mathrm{CgR}$ sustained in $78 \%$ and $\mathrm{CCgR}$ in $83 \%$ ). After a 2-year follow-up, $59 \%$ of patients discontinued nilotinib due to progression $(27 \%)$ or adverse effects $(15 \%)^{(54)}$.

A study included 137 imatinib-resistant $(80 \%)$ or intolerant $(20 \%)$ AP patients in a follow-up of at least 11 months. The responses were: CHR in $31 \%$ with a median time of 1 month to be achieved; major $\mathrm{CgR}$ in $32 \%$ with a median time of 2.8 months, and CCgR in $20 \%$ of patients, of whom $70 \%$ remain in CCgR at 24 months of follow-up, with an OS of $67 \%$ after 2 years ${ }^{(55)}$.

The use of nilotinib in newly-diagnosed CP CML patients was tested in a multicenter study which randomized these patients to receive imatib $400 \mathrm{mg}$, nilotinib $300 \mathrm{mg}$ bid, or nilotinib $400 \mathrm{mg}$ bid.

After 12 months, the MMR rates for nilotinib (44\% at the $300 \mathrm{mg}$ dose and $43 \%$ at the $400 \mathrm{mg}$ dose) were practically double the rate for imatinib (22\%; p $<0.001)$. The CCgR rates at 12 months were higher for nilotinib $(80 \%$ for the $300 \mathrm{mg}$ dose and $78 \%$ for the $400 \mathrm{mg}$ dose) in relation to imatinib (65\%; $\mathrm{p}<0.001)$. There was a significant reduction of PFS with nilotinib ${ }^{(56)}$.

\section{New agents}

Bosutinib (SKI606), an inhibitor 30 times more potent than imatinib, inhibits Src/Abl TK. A phase-I study showed that the $500 \mathrm{mg}$ daily dose was effective. The phase-II study in CP patients who failed imatinib and second-generation TKI is underway.

Preliminary data showed that, among the 69 imatinib-resistant patients, $81 \%$ achieved CHR, $45 \%$ major $\mathrm{CgR}$, including $32 \% \mathrm{CCgR}$. The treatment was well tolerated, and the most common adverse effects were gastrointestinal effects ${ }^{(56)}$.

New TKI are being developed ${ }^{(57)}$ in phase-I studies, with activity on T315I mutation, such as AP24534(58); aurora kinase inhibitors such as PHA-739358 (Nerivano Medical Sciences, Milan, Italy $)^{(58)}$, and KW-2449 (Kyowa Hakko Kirin Pharma, Tokyo, Japan) ${ }^{(58)}$, both with activity against the T315I mutation.

Homoharringtonine (ChemGenex, Victoria, Australia), an apoptosis modulator, was tested in all CML phases in imatinib-resistant patients and secondgeneration TKI-resistant patients; it acts on the T315I mutation. Preliminary results of phase-II studies showed hematologic and cytogenetic responses with disappearance of the T315I clone in $60 \%$ of evaluable patients $^{(58)}$. In a phase-I study, DCC-2036 (Deciphera, Lawrence, Kansas), a non-ATP competitive multiTK inhibitor that acts on the T315I mutation showed significant activity on $\mathrm{Ph}+$ cells $^{(58)}$. 
Leukemia Net's recommendations for CML treatment Imatinib $400 \mathrm{mg} /$ day is the standard treatment for CP CML. IFN is the drug of choice during pregnancy or in low-risk patients presenting with comorbidities or using other medications that make the use of imatinib inadequate.

In imatinib-intolerant patients, the choices are dasatinib or nilotinib. The choice of the agent should be based on the mutational status of the patient as well as on occasional patient's comorbidities. Patients who fail imatinib, particularly with loss of hematologic response, should receive nilotinib or dasatinib. For patients with sub-optimal response, there is no solid evidence, to date, that the change in treatment is beneficial, but an increase in the imatinib dose or change for a secondgeneration TKI may be considered.

Allotransplantation is recommended for patients in AP, BP or with T315I mutation, and for patients who failed second-generation TKI. Occasionally, it may also be considered for patients with sub-optimal response to second-generation TKI, especially if they are high-risk patients.

Naïve AP or BP patients should receive allotransplantation, if eligible, after an initial treatment with imatinib 600 to $800 \mathrm{mg} /$ day or second-generation TKI, if resistant to imatinib. Effective treatment with TKI should not be discontinued and doses should not be reduced below standard doses if significant adverse effects are absent.

\section{CONCLUSION}

The improved understanding of CML biology enabled the development of a highly effective targeted therapy which revolutionized the treatment of CML, thus changing its natural history. Unlike 10 to 15 years ago, $\mathrm{CP}$ patients now have a long expected survival with imatinib.

Second-generation TKI are effective in most of the imatinib-resistant or intolerant patients. However, they are not effective in part of the patients due to other mechanisms, including T315I mutation, which is still a challenge.

A better understanding of resistance mechanisms, as well as the development of new molecules, will contribute to further improvements in the treatment of CML.

\section{REFERENCES}

1. Cortes J. Natural history and staging of chronic myelogenous leukemia. Hematol Oncol Clin North Am. 2004;18(3):569-84

2. Nowell PC, Hungerford DA. A minute chromosome in human chronic granulocytic leukemia [abstract]. Science. 1960;132(3438):1497.
3. Geary CG. The story of chronic myeloid leukaemia. $\mathrm{Br} J$ Haematol. 2000;110(1):2-11

4. Melo JV, Deininger MW. Biology of chronic myelogenous leukemia--signaling pathways of initiation and transformation. Hematol Oncol Clin North Am. 2004;18(3):545-68, vii-viii.

5. Deininger MW, Goldman JM, Melo JV. The molecular biology of chronic myeloid leukemia. Blood. 2000;96(10):3343-56.

6. Tefferi A, Dewald GW, Litzow ML, Cortes J, Mauro MJ, Talpaz M, et al. Chronic myeloid leukemia: current application of cytogenetics and molecular testing for diagnosis and treatment. Mayo Clin Proc. 2005;80(3):390-402.

7. Georgii A, Buesche G, Kreft A. The histopathology of chronic myeloproliferative diseases. Baillieres Clin Haematol. 1998;11(4):721-49.

8. Cortes JE, Talpaz M, OBrien S, Faderl S, Garcia-Manero G, Ferrajoli A, et al. Staging of chronic myeloid leukemia in the imatinib era: an evaluation of the World Health Organization proposal. Cancer. 2006;106(6):1306-15.

9. Faderl S, Talpaz M, Estrov Z, Kantarjian HM. Chronic myelogenous leukemia: biology and therapy. Ann Intern Med. 1999;131(3):207-19.

10. Sokal JE, Cox EB, Baccarani M, Tura S, Gomez GA, Robertson JE, et al. Prognostic discrimination in "good-risk" chronic granulocytic leukemia. Blood. 1984;63(4):789-99.

11. Hasford J, Pfirrmann M, Hehlmann R, Allan NC, Baccarani M, Kluin-Nelemans $\mathrm{JC}$, et al. A new prognostic score for survival of patients with chronic myeloid leukemia treated with interferon alfa. Writing Committee for the Collaborative CML Prognostic Factors Project Group. J Natl Cancer Inst. 1998:90(11):850-8.

12. Galton DA. Myleran in chronic myeloid leukaemia; results of treatment. Lancet. 1953;264(6753):208-13.

13. Hehlmann R, Heimpel H, Hasford J, Kolb HJ, Pralle H, Hossfeld DK, et al. Randomized comparison of interferon-alpha with busulfan and hydroxyurea in chronic myelogenous leukemia. The German CML Study Group. Blood. 1994:84(12):4064-77.

14. Interferon alfa-2a as compared with conventional chemotherapy for the treatment of chronic myeloid leukemia. The Italian Cooperative Study Group on Chronic Myeloid Leukemia. N Engl J Med. 1994;330(12):820-5.

15. Talpaz M, Kantarjian HM, McCredie K, Trujillo JM, Keating MJ, Gutterman JU. Hematologic remission and cytogenetic improvement induced by recombinant human interferon alpha $\mathrm{A}$ in chronic myelogenous leukemia. N Engl $\mathrm{J}$ Med. 1986;314(17):1065-9.

16. Horowitz MM, Rowlings PA, Passweg JR. Allogeneic bone marrow transplantation for CML: a report from the International Bone Marrow Transplant Registry. Bone Marrow Transplant. 1996;17 Suppl 3:S5-6.

17. Goldman JM, Majhail NS, Klein JP, Wang Z, Sobocinski KA, Arora M, et al. Relapse and late mortality in 5-year survivors of myeloablative allogeneic hematopoietic cell transplantation for chronic myeloid leukemia in first chronic phase. J Clin Oncol. 2010;28(11):1888-95.

18. Collins RH Jr, Shpilberg O, Drobyski WR, Porter DL, Giralt S, Champlin R, et al. Donor leukocyte infusions in 140 patients with relapsed malignancy after allogeneic bone marrow transplantation. J Clin Oncol. 1997;15(2):433-44.

19. Talpaz M, Kantarjian HM, McCredie K, Trujillo JM, Keating MJ, Gutterman JU. Hematologic remission and cytogenetic improvement induced by recombinant human interferon alpha A in chronic myelogenous leukemia. N Engl J Med. 1986;314(17):1065-9.

20. Druker BJ, Lydon NB. Lessons learned from the development of an abl tyrosine kinase inhibitor for chronic myelogenous leukemia. J Clin Invest. 2000;105(1):3-7.

21. Druker BJ, Tamura S, Buchdunger E, Ohno S, Segal GM, Fanning S, et al. Effects of a selective inhibitor of the Abl tyrosine kinase on the growth of BcrAbl positive cells. Nat Med. 1996;2(5):561-6.

22. Druker BJ, Talpaz M, Resta DJ, Peng B, Buchdunger E, Ford JM, et al. Efficacy and safety of a specific inhibitor of the BCR-ABL tyrosine kinase in chronic myeloid leukemia. N Engl J Med. 2001;344(14):1031-7. 
23. OBrien SG, Guilhot F, Larson RA, Gathmann I, Baccarani M, Cervantes F, Cornelissen JJ, Fischer T, Hochhaus A, Hughes T, Lechner K, Nielsen JL, Rousselot P, Reiffers J, Saglio G, Shepherd J, Simonsson B, Gratwohl A, Goldman JM, Kantarjian H, Taylor K, Verhoef G, Bolton AE, Capdeville R, Druker BJ; IRIS Investigators. Imatinib compared with interferon and low-dose cytarabine for newly diagnosed chronic-phase chronic myeloid leukemia. N Engl J Med. 2003;348(11):994-1004.

24. Baccarani M, Druker BJ, Cortes-Franco J, Hughes TP, Kim DW, Pane F, et al. 24 months update of the TOPS study: a phase III, randomized, open-label study of $400 \mathrm{mg} / \mathrm{d}$ (SD-IM) versus $800 \mathrm{mg} / \mathrm{d}$ (HD-IM) of imatinib mesylate (IM) in patients (Pts) with newly diagnosed, previously untreated chronic myeloid leukemia in chronic phase (CML-CP) [abstract]. Blood. 2009; 114(22):142-3.

25. Guilhot F, Preudhomme C, Guilhot J, Mahon FX, Nicolini FE, Rigual-Huguet F, et al. Significant higher rates of undetectable molecular residual disease and molecular responses with pegylated form of interferon a2a in combination with imatinib (IM) for the treatment of newly diagnosed chronic phase (CP) Chronic myeloid leukaemia (CML) Patients (pts): confirmatory results at 18 months of part 1 of the spirit phase III randomized trial of the French CML Group (FI LMC) [abstract]. Blood. 114(22):144.

26. Palandri F, lacobucci I, Castagnetti F, Testoni N, Poerio A, Amabile M, Breccia M, Intermesoli T, Iuliano F, Rege-Cambrin G, Tiribelli M, Miglino M, Pane F, Saglio G, Martinelli G, Rosti G, Baccarani M; GIMEMA Working Party on CML. Frontline treatment of Philadelphia positive chronic myeloid leukemia with imatinib and interferon-alpha: 5-year outcome. Haematologica. 2008;93(5):770-4.

27. Baccarani M, Cortes J, Pane F, Niederwieser D, Saglio G, Apperley J, Cervantes F, Deininger M, Gratwohl A, Guilhot F, Hochhaus A, Horowitz M, Hughes T, Kantarjian H, Larson R, Radich J, Simonsson B, Silver RT, Goldman J, Hehlmann R; European LeukemiaNet. Chronic myeloid leukemia: an update of concepts and management recommendations of European LeukemiaNet. J Clin Oncol. 2009;27(35):6041-51.

28. Kantarjian H, Schiffer C, Jones D, Cortes J. Monitoring the response and course of chronic myeloid leukemia in the modern era of BCR-ABL tyrosine kinase inhibitors: practical advice on the use and interpretation of monitoring methods. Blood. 2008;111(4):1774-80.

29. Deininger M, O'Brien S, Guilhot F, Goldman JM, Hochhaus A, Hughes TP, et al. International randomized study of interferon vs STI571 (IRIS) 8-year follow up: sustained survival and low risk for progression or events in patients with newly diagnosed chronic myeloid leukemia in chronic phase (CML-CP) treated with imatinib [abstract]. Blood. 2009;114(22):462.

30. de Lavallade H, Apperley JF, Khorashad JS, Milojkovic D, Reid AG, Bua M, et al. Imatinib for newly diagnosed patients with chronic myeloid leukemia: incidence of sustained responses in an intention-to-treat analysis. J Clin Oncol. 2008;26(20):3358-63.

31. Gorre ME, Mohammed M, Ellwood K, Hsu N, Paquette R, Rao PN, et al. Clinical resistance to STI-571 cancer therapy caused by BCR-ABL gene mutation or amplification. Science. 2001;293(5531):876-80.

32. O'Hare T, Eide CA, Deininger MW. Bcr-Abl kinase domain mutations, drug resistance, and the road to a cure for chronic myeloid leukemia. Blood. 2007;110(7):2242-9.

33. White DL, Saunders VA, Dang P, Frede A, Eadie L, Soverini S, et al. CML patients with low OCT-1 activity achieve better molecular responses on high dose imatinib than on standard dose. Those with high OCT-1 activity have excellent responses on either dose: a TOPS correlative study [abstract]. Blood. 2008; 112(11):1093-4.

34. Gambacorti-Passerini C, Barni R, le Coutre P, Zucchetti M, Cabrita G, Cleris $L$, et al. Role of alpha1 acid glycoprotein in the in vivo resistance of human BCR-ABL(+) leukemic cells to the abl inhibitor STI571. J Natl Cancer Inst. 2000;92(20):1641-50.

35. Meyn MA 3rd, Wilson MB, Abdi FA, Fahey N, Schiavone AP, Wu J, et al. Src family kinases phosphorylate the Bcr-Abl SH3-SH2 region and modulate BcrAbl transforming activity. J Biol Chem. 2006;281(41):30907-16.

36. Jabbour E, Kantarjian H, Jones D, Talpaz M, Bekele N, O'Brien S, et al. Frequency and clinical significance of BCR-ABL mutations in patients with chronic myeloid leukemia treated with imatinib mesylate. Leukemia. 2006;20(10):1767-73.
37. Shah NP, Tran C, Lee FY, Chen P, Norris D, Sawyers CL. Overriding imatinib resistance with a novel ABL kinase inhibitor. Science. 2004;305(5682):399-401.

38. Tokarski JS, Newitt JA, Chang CY, Cheng JD, Wittekind M, Kiefer SE, et al. The structure of Dasatinib (BMS-354825) bound to activated ABL kinase domain elucidates its inhibitory activity against imatinib-resistant ABL mutants. Cancer Res. 2006;66(11):5790-7.

39. Kantarjian H, Pasquini R, Levy V, Jootar S, Holowiecki J, Hamerschlak N, et al. Dasatinib or high-dose imatinib for chronic-phase chronic myeloid leukemia resistant to imatinib at a dose of 400 to 600 milligrams daily: twoyear follow-up of a randomized phase 2 study (START-R) [abstract]. Cancer. 2009;115(18):4136-7,

40. Shah NP, Kantarjian HM, Kim DW, Réa D, Dorlhiac-Llacer PE, Milone JH, et al. Intermittent target inhibition with dasatinib $100 \mathrm{mg}$ once daily preserves efficacy and improves tolerability in imatinib-resistant and-intolerant chronicphase chronic myeloid leukemia. J Clin Oncol. 2008;26(19):3204-12.

41. Hochhaus A, Kantarjian HM, Baccarani M, Lipton JH, Apperley JF, Druker BJ, et al. Dasatinib induces notable hematologic and cytogenetic responses in chronic-phase chronic myeloid leukemia after failure of imatinib therapy. Blood. 2007;109(6):2303-9.

42. Hochhaus A, Baccarani M, Deininger M, Apperley JF, Lipton JH, Goldberg $\mathrm{SL}$, et al. Dasatinib induces durable cytogenetic responses in patients with chronic myelogenous leukemia in chronic phase with resistance or intolerance to imatinib. Leukemia. 2008;22(6):1200-6.

43. Baccarani M, Rosti G, Saglio G, Cortes J, Stone R, Niederwieser D, et al. Dasatinib time to and durability of major and complete cytogenetic response (MCyR and CCyR) in patients with chronic myeloid leukemia in chronic phase (CML-CP) [abstract]. Blood. 2008;112(11):172.

44. Kantarjian H, Shah NP, Hochhaus A, Cortes J, Shah S, Ayala M, et al. Dasatinib versus imatinib in newly diagnosed chronic-phase chronic myeloid leukemia. N Engl J Med. 2010;362(24):2260-70.

45. Shah NP, Kim DW, Kantarjian HM, Rousselot P, Dorlhiac-Llacer PE, Milone JH, et al. Dasatinib $50 \mathrm{mg}$ or $70 \mathrm{mg}$ BID compared to $100 \mathrm{mg}$ or $140 \mathrm{mg}$ QD in patients with $\mathrm{CML}$ in chronic phase (CP) who are resistant or intolerant to imatinib: one-year results of CA180034 [abstract]. J Clin Oncol. 2007;25(18S): Abstract 7004.

46. Kantarjian H, Cortes J, Kim DW, Dorlhiac-Llacer P, Pasquini R, DiPersio J, et al. Phase 3 study of dasatinib $140 \mathrm{mg}$ once daily versus $70 \mathrm{mg}$ twice daily in patients with chronic myeloid leukemia in accelerated phase resistant or intolerant to imatinib: 15-month median follow-up. Blood. 2009;113(25):6322-9.

47. Larson RA, Ottmann OG, Shah NP, Lilly M, Reiffers J, Charbonnier A, et al. Dasatinib $140 \mathrm{mg}$ once daily (OD) has equivalent efficacy and improved safety compared with $70 \mathrm{Mg}$ twice daily (BID) in patients with imatinib-resistant or -intolerant Philadelphia chromosome-positive acute lymphoblastic leukemia (Ph + ALL): 2-year data from CA180-035. Blood. 2008;112(11):1006-7.

48. Weisberg E, Manley PW, Breitenstein W, Brüggen J, Cowan-Jacob SW, Ray A, et al. Characterization of AMN107, a selective inhibitor of native and mutant Bcr-Abl. Cancer Cell. 2005;7(2):129-41.

49. Golemovic M, Verstovsek S, Giles F, Cortes J, Manshouri T, Manley PW, et al. AMN107, a novel aminopyrimidine inhibitor of Bcr-Abl, has in vitro activity against imatinib-resistant chronic myeloid leukemia. Clin Cancer Res. 2005;11(13):4941-7.

50. Kantarjian H, Giles F, Wunderle L, Bhalla K, OBrien S, Wassmann B, et al. Nilotinib inimatinib-resistant CML and Philadelphia chromosome-positive ALL. N Engl J Med. 2006;354(24):2542-51.

51. Kantarjian HM, Giles F, Gattermann N, Bhalla K, Alimena G, Palandri F, et al. Nilotinib (formerly AMN107), a highly selective BCR-ABL tyrosine kinase inhibitor, is effective in patients with Philadelphia chromosome-positive chronic myelogenous leukemia in chronic phase following imatinib resistance and intolerance. Blood. 2007;110(10):3540-6.

52. Plosker GL, Robinson DM. Nilotinib. Drugs. 2008;68(4):449-59; discussion 460-1.

53. Deininger MW. Nilotinib. Clin Cancer Res. 2008;14(13):4027-31. 
54. Kantarjian H, Giles F, Bhalla K, Pinilla-lbarz J, Larson RA, Gattermann N, et al. Update on imatinib-resistant chronic myeloid leukemia patients in chronic phase (CML-CP) on nilotinib therapy at 24 months: clinical response, safety, and long-term outcomes [abstract]. Blood. 2009;114(22):464.

55. Hochhaus A, Giles F, Apperely J, Ossenkoppele G, Wang J, Gallagher NJ, et al. Nilotinib in chronic myeloid leukemia patients in accelerated phase (CML-AP) with imatinib resistance or intolerance: 24-month follow-up results of a phase 2 study [abstract]. Haematologica. 2009;94(Suppl 2):256.

56. Saglio G, Kim DW, Issaragrisil S, le Coutre P, Etienne G, Lobo C, Pasquini R, Clark RE, Hochhaus A, Hughes TP, Gallagher N, Hoenekopp A, Dong M,
Haque A, Larson RA, Kantarjian HM; ENESTnd Investigators. Nilotinib versus imatinib for newly diagnosed chronic myeloid leukemia. N Engl J Med. 2010;362(24):2251-9.

57. Cortes J, Kantarjian HM, Kim DW, Khoury HJ, Turkina AG, Shen ZX, et al. Efficacy and safety of bosutinib (SKI-606) in patients with chronic phase (CP) Ph plus chronic myelogenous leukemia (CML) with resistance or intolerance to imatinib [abstract]. Blood. 2008;112(11):401.

58. Bixby D, Talpaz M. Mechanisms of resistance to tyrosine kinase inhibitors in chronic myeloid leukemia and recent therapeutic strategies to overcome resistance. Hematology Am Soc Hematol Educ Program. 2009:461-76. 